\title{
Comparison of pollutant emission associated with the operation of passenger cars with internal combustion engines and passenger cars with electric motors
}

\author{
Katarzyna Bebkiewicz ${ }^{1} \cdot$ Zdzisław Chłopek $^{2} \cdot$ Hubert Sar $^{2}$ (D) Krystian Szczepański $^{3}$
}

Received: 22 October 2020 / Accepted: 9 January 2021 / Published online: 21 January 2021

(c) The Author(s) 2021

\begin{abstract}
Energy consumption and pollutant emission aspects were ascertained for cars under traffic conditions: in cities, outside cities, on motorways and expressways, with the use of data from the inventory of emissions from road transport in Poland in 2018. The values of characteristics of energy consumption under model traffic conditions, as well as pollutant emissions and energy consumption of cars with internal combustion engines and cars with electric motors, constituted the basis for further analyses and conclusions about the characteristics of the vehicles under the study in terms of energy consumption and pollutant emissions. As a result of the research, it was found in the case of the use of electric drives, a very significant decrease in energy consumption—by $70 \%$ and the emission of non-methane volatile organic compounds—at the level of $90 \%$. In the case of the emission of nitrogen oxides, there is a great advantage in relation to cars with compression-ignition engines, while the emission of nitrogen oxides from cars with spark-ignition engines is about two times lower. It was found that the emission of particulate matter for electric cars is about three times higher than for cars with compression-ignition engines and almost six times higher than for cars with spark-ignition engines. On the other hand, the impact on carbon dioxide emissions is small-less than $10 \%$.
\end{abstract}

\section{Introduction}

The environmental benefits of decreasing pollutant emissions from motor vehicles (EV) are unquestionable. Maintaining healthy natural environment is particularly important in the areas where a great number of people can be

Hubert Sar

hubert.sar@pw.edu.pl

Katarzyna Bebkiewicz

katarzyna.bebkiewicz@kobize.pl

Zdzisław Chłopek

zdzislaw.chlopek@pw.edu.pl

Krystian Szczepański

krystian.szczepanski@ios.edu.pl

1 Institute of Environmental Protection - National Research Institute, National Centre for Emissions Management (KOBiZE), 132/134 Chmielna Str., 00-805 Warsaw, Poland

2 Institute of Vehicles and Construction Machinery Engineering, Warsaw University of Technology, 84 Narbutta Str., 02-524 Warsaw, Poland

3 Institute of Environmental Protection, National Research Institute, 5/11D Krucza Str., 00-548 Warsaw, Poland exposed to intense pollution from cars, such as large urban agglomerations [1,2]. Even though the commercial term "zero-emission vehicles" is used to describe cars with electric motors (electric vehicles-EVs), they still contribute to the emission of particulate matter under local conditions, as a result of the tribological processes ongoing in cars operating on the road surface, as well as the processes associated with stirring up road surface dusts [1,3-6]. Yet, particulate matter emissions from electric vehicles are lower as compared to those from conventional cars (internal combustion engine vehicles), because friction is less responsible for braking EVs, as electric braking is generally used in that case. In consideration of the above, environmental benefits of electric vehicles are substantial on a local scale. As one of the fundamental priorities of environmental protection is to counteract emissions of greenhouse gases (GHGs) which significantly add to the intensification of the greenhouse effect and, consequently, enhance climate change [7-9] that poses severe risks at a global level. The emissions of other pollutants associated with car use are also of global importance $[3,5,6,10-12]$. Hence, apart from the examination of pollutants emitted by cars on a local scale, there has been carried out the overall inventory of pollutant emissions from 
road transport. In Poland, such an inventory has been carried out by the National Centre for Emissions Management (KOBiZE) established at the Institute of Environmental Protection-National Research Institute (IOŚ-PIB) [3, 6, 8, 9]. The inventory results are reported annually to the European Union authorities [12]. In other world's countries, pollutant emission inventories have been also carried out and their results have been far and wide disseminated [10].

In the case of electric vehicles, global pollutant emissions are significantly different when compared to those on a local scale. For the purpose of the present study, it was assumed that pollutant emission from electricity generation (even though it is included in the emission inventory) would not be taken into account in the comparative analyses carried out-pollutant emission from electric cars on a global scale originate no more than from the processes of electricity generation and transmission. Therefore, in order to assess global environmental effects of electric vehicle operations, it was necessary to take into consideration the characteristics of the processes of generation and transmission of electric energy used to charge EV batteries [13].

An assessment of the ecological effects of the development of electromobility can be conducted in a much more comprehensive manner, primarily with the use of the life cycle assessment (LCA) method [4]. The work [4] considers the processes related to the production, operation and disposal of vehicles after their use. The obtained results show a very high sensitivity of the ecological properties of electric cars to the technology of electricity generation. In Poland, where most of the electricity comes from the combustion of hard coal and lignite, the use of electric cars may cause a greater burden on the environment than the use of cars with internal combustion engines.

Most of the publications related to the operational properties of electric drive cars are devoted to energy consumption, for example [14]. Also, the article [15] presents the results of research on energy consumption by Citroen Berlingo converted into an electric car. It has been shown that under ECE 15 test conditions [16], the overall efficiency of an electric car is relatively better than that of comparable models with combustion engines by (12.2-43.3)\%. The paper [17] presents the results of comparative studies of energy consumption by an electric car and a car with an internal combustion engine in real conditions during operation in Erfurt. A relative improvement in the overall efficiency of an electric car was found in relation to a car with an internal combustion engine by $68 \%$ in the driving test and by as much as $77 \%$ in urban driving conditions. Similar results were obtained in the 5-month test studies presented in the article [18]. Because in a large part of the articles on electric cars, the subject of research is energy consumption, their subject matter in the field of pollutant emissions concerns only fossil carbon dioxide emissions.
Energy consumption and pollutant emissions associated with the use of passenger cars, equipped with either internal combustion engines (Euro 6 emission standard) or electric motors, were comparatively assessed. INFRAS AG software was used to determine the characteristics of energy consumption and pollutant emissions from cars with internal combustion engines. Pollutant emissions from electric motor vehicles were determined based on car energy consumption characteristics and characteristics of pollutant emissions in the processes of electricity generation and transmission under the conditions of Poland's energy sector.

The present study was undertaken with the aim to evaluate the environmental effects of electric cars because of their pollutant emissions on a global scale, shaped under the traffic conditions described in the authorized inventory of emissions from road transport in Poland. The analyses carried out concerned passenger vehicles. The most modern cars equipped with internal combustion engines (Euro 6 emission standard) were compared with electric motor cars [16].

\section{Methodology}

As zero-dimensional characteristics of energy consumption, fuel consumption and pollutant emissions, there were assumed the following aspects: distance energy consumption, distance fuel consumption and pollutant emissions [11].

Distance energy consumption (en) is a derivative of energy consumption in relation to the distance travelled by the vehicle

en $=\frac{\mathrm{dEN}}{\mathrm{d} s}$,

where EN—energy consumed by the car,

$s$-distance travelled by the car.

Energy consumption is usually characterized by distance energy consumption, expressed in a measurement unit referring to operational fuel consumption $(\mathrm{kWh} / 100 \mathrm{~km})$. Energy consumption characteristics, expressed in $\mathrm{kWh} / 100 \mathrm{~km}$, are referred to as operational energy consumption (QEN).

Distance fuel consumption (q) is derived from the mass of fuel consumed in relation to the distance travelled by the vehicle:

$q=\frac{\mathrm{d} m_{f}}{\mathrm{~d} s}$,

where $m_{\mathrm{f}}$-mass of fuel used,

$s$-distance travelled by the car.

The specific distance emission of a pollutant " $\mathrm{x}$ " $\left(b_{\mathrm{x}}\right)$ is a derivative of pollutant emission in relation to the distance travelled by the vehicle: 
$b_{x}=\frac{\mathrm{d} m_{x}}{\mathrm{~d} s}$,

where $\underline{m}_{\mathrm{x}}$-emission of pollutant "x" from the car,

$\underline{s}$-distance travelled by the car.

For the assessment of pollutant emissions from electric vehicles, there was used the energy factor for pollutant emissions during the processes of electricity generation and transmission as a zero-dimensional characteristic of pollutant emissions.

The energy factor of the emission of " $x$ " pollutant from the electric vehicle is a derivative of " $x$ " pollutant emission during the processes of electricity generation and transmission, under the conditions of Poland's energy sector, in relation to energy consumption of the electric vehicle:

$\mathrm{WEN}_{x}=\frac{\mathrm{d} m_{x}}{\mathrm{dEN}}$

where $m_{\mathrm{x}}$-emission of pollutant " $\mathrm{x}$ " in the processes of electricity generation and transmission under the conditions of Poland's energy sector,

EN—energy consumed by the electric vehicle.

In this study, the analysis of emissions was carried out for the pollutants included in the inventory of emissions during the processes of electricity generation and transmission under the conditions of Poland's energy sector (Table 1) [13, 19]:

- Carbon dioxide (CO2)

- Non-methane volatile organic compounds (NMVOC)

- Oxides of nitrogen, reduced to nitrogen dioxide $\left(\mathrm{NO}_{\mathrm{X}}\right)$

- Total particulate matter (PM)

For the determination of energy consumption and pollutant emissions from passenger cars equipped with internal combustion engines, there were selected the cars compliant with the Euro 6 emission standard [16]:

- with spark-ignition engines

- with compression-ignition engines

Table 1 Energy factor for pollutant emission from electricity generation and transmission under the conditions of the energy sector in Poland

\begin{tabular}{ll}
\hline Pollutant & $\begin{array}{l}\text { Energy factor } \\
\mathrm{g} /(\mathrm{kW} \bullet \mathrm{h})\end{array}$ \\
\hline $\mathrm{CO}_{2}$ & 765 \\
$\mathrm{NMVOC}$ & 0.0040 \\
$\mathrm{NO}_{\mathrm{x}}$ & 0.631 \\
$\begin{array}{l}\text { Total particulate } \\
\text { matter }\end{array}$ & 0.036 \\
\hline
\end{tabular}

Distance energy consumption for electric vehicles was determined using the results of:

- Approval tests-NEDC (New European Driving Cycle), WLTC (Worldwide Harmonized Light vehicles Test Cycles) and FTP-75 (Federal Test Procedure) [16]

- The studies with the use of specific tests, for example, Stop and Go (test simulating traffic jams) [20], Autobahn (test simulating traffic on motorways and expressways) [20]

- In-service tests under the actual use conditions

Distance energy consumption and the specific distance emission of pollutants from internal combustion engines were assessed for the conditions simulating the actual use of cars, determined under the framework of the inventory of emissions from road transport [3, 6, 8, 9], carried out by the National Centre for Emissions Management (KOBiZE) $[6,9]$, compliant with the EEA/EMEP Emission Inventory Guidebook 2019 [14] and 2006 IPCC Guidelines for National Greenhouse Gas Inventories [7].

INFRAS AG software [21] was used to determine the characteristics of pollutant emissions and fuel consumption of Euro 6 passenger cars. The analysed characteristics included: distance fuel consumption and the specific distance emission of pollutants. Based on distance fuel consumption, there was determined operational energy consumption based on the assumed calorific values of fuels [22]:

- motor gasoline: $44.3 \mathrm{MJ} / \mathrm{kg}$

- diesel fuel: $43.0 \mathrm{MJ} / \mathrm{kg}$

Distance fuel consumption and the specific distance emissions were determined in reference to the classification used in INFRAS AG software for car technical parameters applicable in the year 2020, with regard to the engine combustion system of the conventional car size-specified by internal combustion engine displacement volume:

- spark-ignition engines with displacement volume:

- Vss $<1.4 \mathrm{dm}^{3}$ —car category: "small"

- $1.4 \mathrm{dm}^{3} \leq \mathrm{Vss}<2.0 \mathrm{dm}^{3}$ — car category: "medium"

- Vss $\geq 2.0 \mathrm{dm}^{3}$ — car category: "large"

- compression-ignition engines with displacement volume:

- Vss $<1.4 \mathrm{dm}^{3}$ —car category: "small"

- $1.4 \mathrm{dm}^{3} \leq \mathrm{Vss}<2.0 \mathrm{dm}^{3}$ - car category: "medium"

- Vss $\geq 2.0 \mathrm{dm}^{3}$ — car category: "large"

Distance fuel consumption and the specific distance emission of pollutants from internal combustion engines 


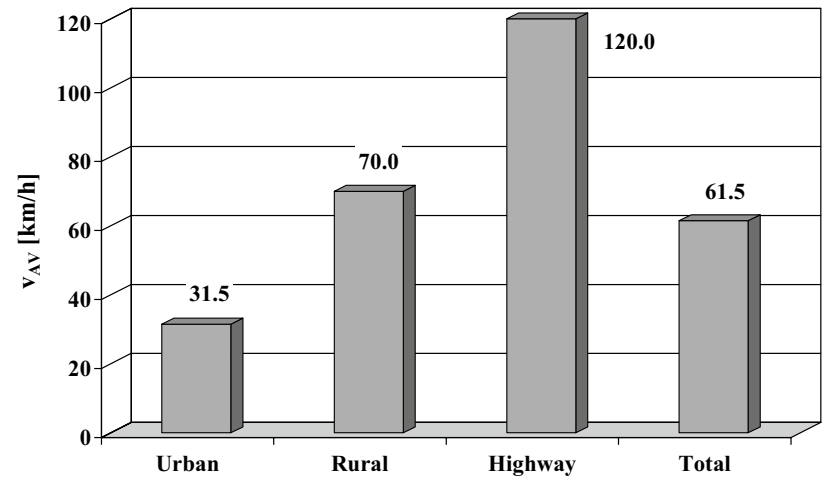

Fig. 1 Average speed of passenger cars under model traffic conditions: in cities, outside cities, on motorways and expressways and throughout the whole period of operation

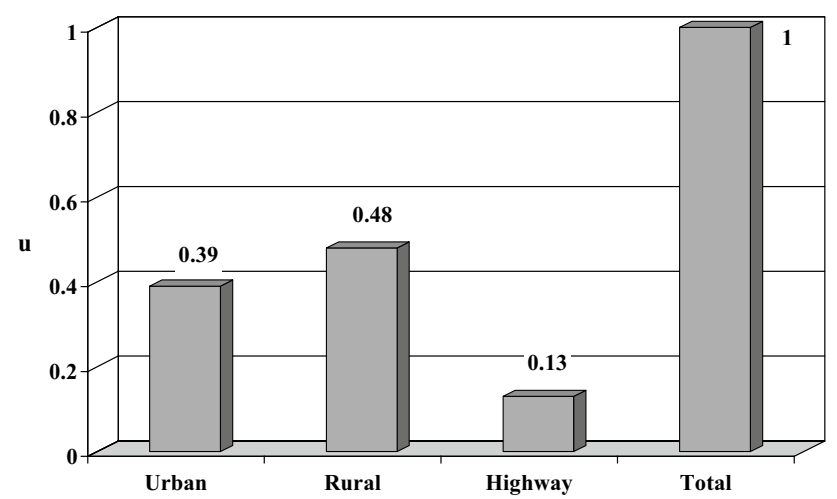

Fig. 2 Share of the length of roads used by passenger cars under model traffic conditions: in cities, outside cities, on motorways and expressways, and throughout the whole period of operation

were determined for the traffic conditions of passenger cars approximately equivalent to the model conditions in Poland's inventory of emissions (Figs. 1 and 2), [6, 9], that is:

- Car traffic in cities, the average car speed-31.5 km/h, the travelled distance share in the total distance travelled by the car under all conditions: 0.39

- Car traffic outside cities, the average car speed- $-70 \mathrm{~km} / \mathrm{h}$, the travelled distance share in the total distance travelled by the car under all conditions: 0.48

- Car traffic on motorways and expressways, the average speed $-120 \mathrm{~km} / \mathrm{h}$, the travelled distance share in the total distance travelled by the car under all conditions: 0.13

- Car traffic under all conditions, the average speed of $61.5 \mathrm{~km} / \mathrm{h}$

The values of operational energy consumption by electric vehicles (travelling at different average speeds) were approximated in the average speed domain, and then operational energy consumption was determined for car speed under model conditions, equivalent to those for cars with internal combustion engines.

All characteristics were determined for passenger car's segments, with reference to electric cars of the conventional size, defined by the maximum vehicle mass, that is:

- $\mathrm{m}_{\max }<1050 \mathrm{~kg}$ - car category: "small"

- $1050 \mathrm{~kg} \leq \mathrm{m}_{\max }<1400 \mathrm{~kg}$ —car category: "medium"

- $\mathrm{m}_{\max } \geq 1400 \mathrm{~kg}$ — car category: "large"

The values determined under the model traffic conditions of passenger cars: operational energy consumption and the specific distance emission of pollutants from cars with internal combustion engines and those with electric motors were the basis for further analyses and the conclusions drawn as regards the properties of the tested vehicles in terms of energy consumption and pollutant emissions.

\section{Results and discussions}

\section{Pollutant emissions associated with energy consumption of electric vehicles}

The primary measure used in the analysis of pollutant emissions associated with electric vehicle operation is energy consumption, for the reason that electric cars emit practically no pollutants during operation. In actual fact, however, there occurs particulate matter emission, as a result of the tribological processes that take place mostly during car braking, as well as the processes related to cooperation of car wheels with the road surface.

In the present study, the emission of particulate matter from sources other than combustion engines was not taken into account. As assumed, the emissions associated with the use of electric vehicles are those related to generation and transmission of electric energy. In view of that, pollutant emissions depend on the technologies of power generation. The analyses carried out in this study were based on data on the energy sector in Poland.

Available data on energy consumption by electric vehicles is fairly inconsistent. The studies carried out under the conditions of vehicle operation show that the results on energy consumption obtained in type-approval tests can significantly differ from the values obtained under factual conditions of vehicle use.

The study [23] presents test results of energy consumption by the electric vehicle Zilent Courant manufactured in China. Figure 3 presents the results of simulation tests of the car under pseudo-random operating conditions using the Monte Carlo method. The graph shows the points depicting 


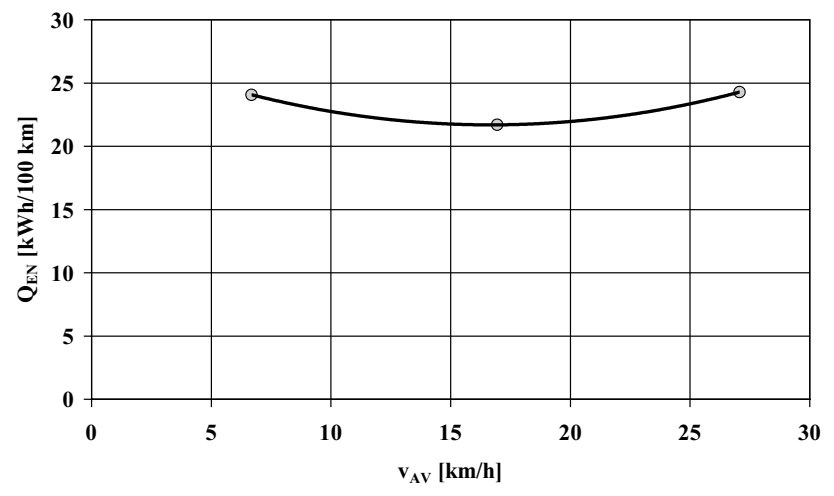

Fig. 3 Dependence of operational energy consumption of the electric vehicle on car average speed (based on data from [23])

the values of average operational energy consumption and the average car speed, under the conditions equivalent to driving in traffic jams, as well as in cities with differentiated traffic. It is clearly visible that energy consumption of the electric car is quite insensitive to urban traffic conditions. This property is fundamentally different than for cars with internal combustion engines, for which energy consumption is strongly dependent on the vehicle speed, which characterizes the vehicle movement patterns, for example, in traffic jams, in cities, outside cities and on highways and expressways [5, 20,21]. For an electric car, it is particularly important that in conditions of significant traffic difficulties, that is, at a low average speed, there is practically no increase in energy consumption, unlike in the case of cars with internal combustion engines, especially those with spark-ignition engines [5, 20, 21].

The paper [18] presents the results of operational testing of the specific electric vehicle-Nissan D-21 converted into the electric car. This car is equipped with an electric motor with nominal $37 \mathrm{~kW}$. The research was carried out in a much wider range in terms of the average speed of the car than in the research, the results of which were published in the article [23]. Figure 4 shows operational energy consumption on four types of routes-with considerably different traffic conditions.

The graph clearly shows the strong influence of the average load on energy consumption, depending on the average speed. In the case of cars with combustion engines, a significant increase in energy consumption occurs typically at the average speed which is much higher [20, 21].

The paper [15] presents the results of the energy consumption by the electric vehicle Citroën Berlingo, examined in the driving tests (at the average speeds: $32.7 \mathrm{~km} / \mathrm{h}$ and $21.6 \mathrm{~km} / \mathrm{h}$ ). Figure 5 shows the results obtained in the tests repeated 4 times each. The average speed value and the value of operational energy consumption in each test are marked "AV".

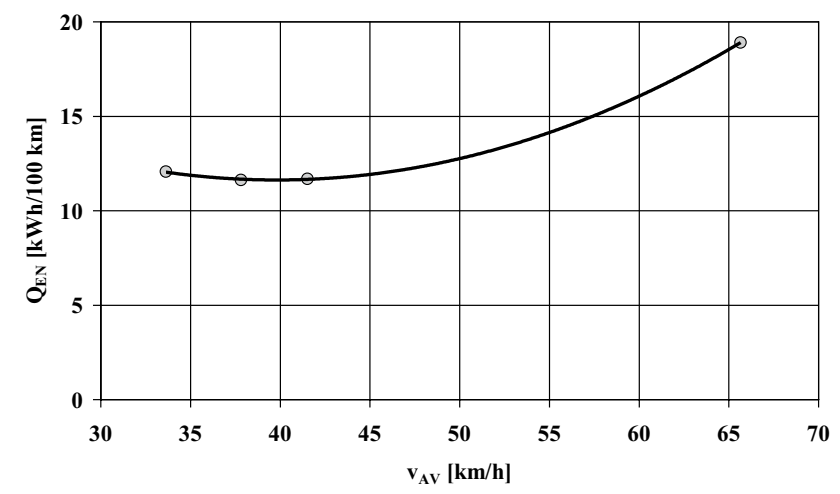

Fig. 4 Operational energy consumption by the electric vehicle on four routes tested, depending on the average car speed (based on data from [18])

Also, in this case, low sensitivity of the electric car's energy consumption to the average speed in the range of the average speed of (20-35) $\mathrm{km} / \mathrm{h}$ was found.

The paper [24] presents the results of tests carried out on the electric vehicle: Volkswagen Lupo EL, under various conditions: in cities, outside cities, on expressways and motorways. Figure 6 shows the dependence between operational energy consumption of the tested vehicle and the average speed. An increase in operational energy consumption is observed at the average speed of about $50 \mathrm{~km} / \mathrm{h}$ and above. The results presented in this publication are consistent with the results from the article [23].

Based on data from the study [15], the dependence between operational energy consumption by electric cars and their maximum masses was examined-Fig. 7. This dependence can be approximated with a linear function.

Using the determined dependence between operational energy consumption of electric cars and their maximum masses, based on data from the study [15] and data on the average EV speed from the study [24], there was built the

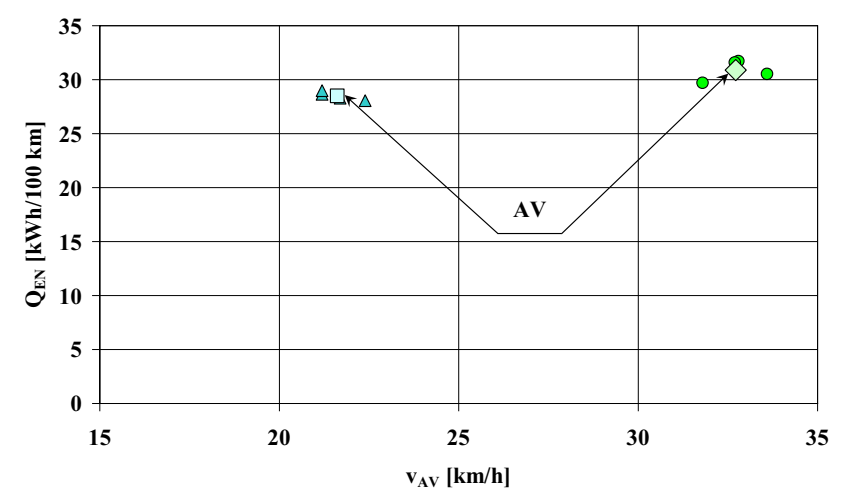

Fig. 5 Operational energy consumption by the electric vehicle examined in two driving tests 


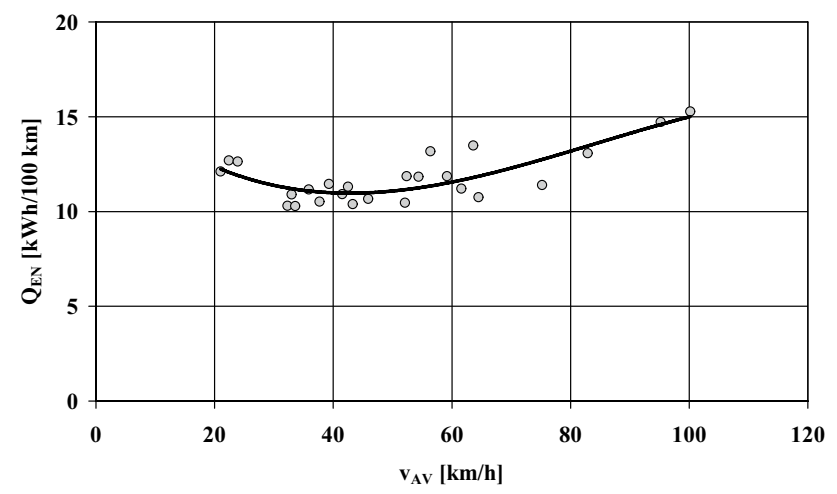

Fig. 6 Dependence between operational energy consumption by the electric car and the average car speed (based on data from [24])

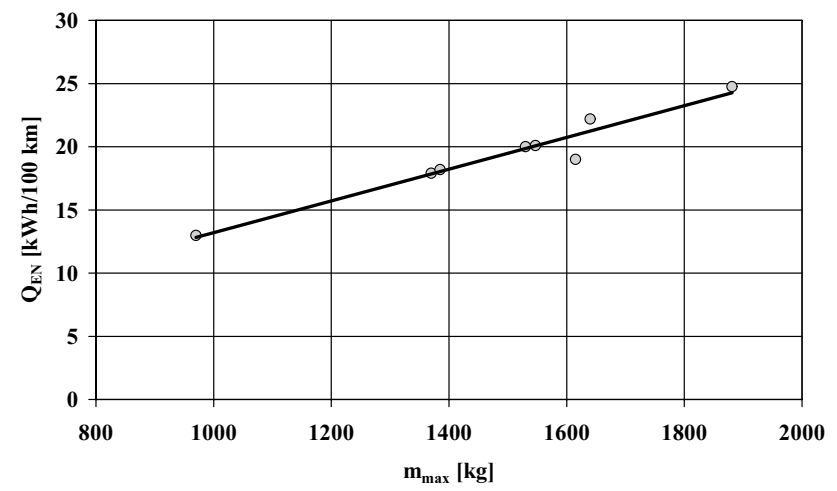

Fig. 7 Dependence between operational energy consumption of electric cars and their maximum masses (based on data from [15])

mathematical model of operational energy consumptiondeveloped in reference to the criterion of functional similarity [25]. The model allowed to conclude the results for traffic conditions used in Poland's emission inventory for the electric vehicle segments: "small", "medium" and "large"— Figs. 8 and 9.

The mathematical model of operational energy consumption of electric cars was adopted as a function of the average speed and vehicle maximum mass:

$Q_{\mathrm{EN}}=F\left(v_{\mathrm{AV}}, m_{\max }\right)$,

where $v_{\mathrm{AV}}$-average car speed,

$m_{\max }$-maximum car mass.

There was assumed the following structure of the mathematical model of operational energy consumption by the electric car:

$Q_{\mathrm{EN}}=\left(a_{1} \cdot v_{\mathrm{AV}}^{2}+a_{2} \cdot v_{\mathrm{AV}}+a_{3}\right) \cdot \frac{m_{\mathrm{max}}}{m_{\mathrm{ref}}}$,

where $v_{\mathrm{AV}}[\mathrm{km} / \mathrm{h}]$ —average car speed,

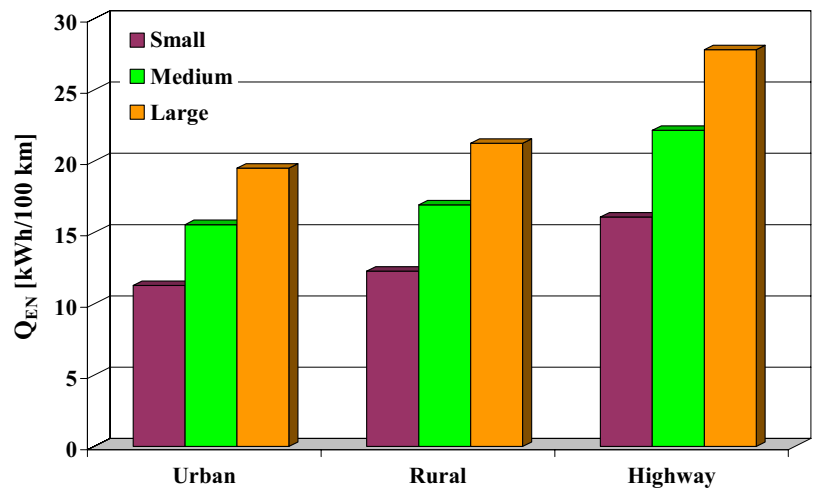

Fig. 8 Operational energy consumption of electric cars from "small", "medium" and "large" segments under traffic conditions: in cities, outside cities, on motorways and expressways, throughout the whole period of operation - the results of modelling

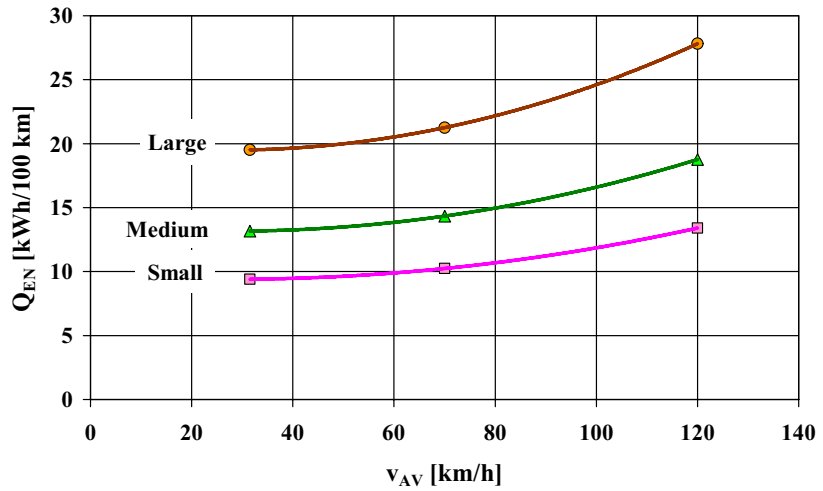

Fig. 9 Dependence between operational energy consumption of electric cars from "small", "medium" and "large" segments and the average speed under traffic conditions: in cities, outside cities, on motorways and expressways - the results of modelling

Table 2 Identified parameters of the operational model of energy consumption by the electric vehicle

\begin{tabular}{ll}
\hline Parameter & Value \\
\hline $\mathrm{a}_{1}$ & $-1.8529 \bullet 10^{-5}$ \\
$\mathrm{a}_{2}$ & $4.6658 \bullet 10^{-3}$ \\
$\mathrm{a}_{3}$ & -0.29740 \\
$\mathrm{~m}_{\text {ref }}$ & 875 \\
\hline
\end{tabular}

$m_{\max }[\mathrm{kg}]$-maximum car mass,

$a=\left[\mathrm{a}_{1}, \mathrm{a}_{2}, \mathrm{a}_{3}\right]$ —model parameters,

$m_{\text {ref }}$-maximum reference car mass (the model parameter).

Based on the results obtained in the studies [15, 24], the parameters of the model were identified-Table 2 . The identification made was consistent with the rule of minimum squares [26]. 
Figures 8 and 9 show the results of modelling-operational energy consumption of electric cars from the "small", "medium" and "large" vehicle segments.

The results of the mathematical model of operational energy consumption by electric cars confirm the results of empirical research, namely:

- Low sensitivity of operational energy consumption to the average speed of travel in the range of low average speed of $(30-50) \mathrm{km} / \mathrm{h}$

- Higher sensitivity of operational energy consumption to the average speed of travel in the range of low average speed of (50-120) km/h

- High sensitivity of operational energy consumption to the parameter characterizing the car size segment, thus to the maximum vehicle mass

The use of the value of the energy factor for pollutant emission during electricity generation and transmission (under the conditions of the energy sector in Poland, Table 1) and the value of operational energy consumption made it possible to determine the specific distance emission corresponding to environmental pollution associated with electric cars in service.

The comparison between the results obtained on energy consumption and the specific distance emissions associated with the use of internal combustion engine cars with those associated with the use of electric cars are presented in subparagraph 3.3 of this article.

\section{Pollutant emissions from passenger cars with internal combustion engines}

Data from INFRAS AG software were used to determine the specific distance emissions of pollutants, distance fuel consumption and operational energy consumption of Euro 6 passenger cars. There were used the models of traffic with the average speed close to the average speed adopted in the authorized inventory of emissions from road transport in Poland.

The results on the specific distance emissions, distance fuel consumption and operational energy consumption of Euro 6 passenger cars, with spark-ignition engines and compression-ignition engines, of conventional size: "small", "medium" and "large", depending on the engine displacement, are presented in Tables 3-6.

As it can be seen from Tables 3 and 4, specific distance emission of particular pollutants is highly sensitive to both vehicle traffic conditions, characterized by the average speed, and the conventional size of the vehicle, depending on the displacement volume of the engine used, as well as to the type of engine: spark ignition and compression ignition. Specific distance emission of nitrogen
Table 3 Specific distance emission of pollutants from cars with spark-ignition engines, from "small", "medium" and "large" segments, under model traffic conditions

\begin{tabular}{|c|c|c|c|c|}
\hline \multirow[t]{2}{*}{ Pollutant } & \multirow{2}{*}{$\begin{array}{l}\mathrm{v}_{\mathrm{AV}} \\
\mathrm{km} / \mathrm{h}\end{array}$} & $\begin{array}{l}\text { Small } \\
\mathrm{b}\end{array}$ & Medium & Large \\
\hline & & \multicolumn{3}{|l|}{$\frac{\mathrm{b}}{\mathrm{g} / \mathrm{km}}$} \\
\hline \multirow[t]{3}{*}{$\mathrm{CO}_{2}$} & 31.0 & 127.0 & 146.9 & 200.5 \\
\hline & 71.1 & 89.2 & 104.9 & 138.6 \\
\hline & 122.0 & 124.0 & 145.8 & 192.5 \\
\hline \multirow[t]{3}{*}{ NMVOC } & 31.0 & 0.0052 & 0.0052 & 0.0052 \\
\hline & 71.1 & 0.0034 & 0.0034 & 0.0034 \\
\hline & 122.0 & 0.0060 & 0.0060 & 0.0060 \\
\hline \multirow[t]{3}{*}{$\mathrm{NO}_{\mathrm{x}}$} & 31.0 & 0.0685 & 0.0685 & 0.0685 \\
\hline & 71.1 & 0.0367 & 0.0367 & 0.0367 \\
\hline & 122.0 & 0.0541 & 0.0541 & 0.0541 \\
\hline \multirow[t]{3}{*}{ PM } & 31.0 & 0.00048 & 0.00048 & 0.00048 \\
\hline & 71.1 & 0.00075 & 0.00075 & 0.00075 \\
\hline & 122.0 & 0.00225 & 0.00225 & 0.00225 \\
\hline
\end{tabular}

Table 4 Specific distance emission of pollutants from cars with compression-ignition engines, from "small", "medium" and "large" segments, under model traffic conditions

\begin{tabular}{lcccc}
\hline Pollutant & \multicolumn{3}{l}{$\begin{array}{l}\text { Small } \\
\text { nedium }\end{array}$} & Large \\
& $\mathrm{v}_{\mathrm{AV}}$ & $\mathrm{b}$ & & \\
\cline { 3 - 5 } & $\mathrm{km} / \mathrm{h}$ & $\mathrm{g} / \mathrm{km}$ & & \\
\hline $\mathrm{CO}_{2}$ & 31.0 & 118.2 & 144.1 & 190.1 \\
& 71.1 & 66.3 & 85.7 & 111.1 \\
& 122.0 & 82.6 & 106.7 & 138.4 \\
$\mathrm{NMVOC}$ & 31.0 & 0.0145 & 0.0145 & 0.0145 \\
& 71.1 & 0.0080 & 0.0080 & 0.0080 \\
& 122.0 & 0.0060 & 0.0060 & 0.0060 \\
$\mathrm{NO}_{\mathrm{x}}$ & 31.0 & 0.243 & 0.243 & 0.243 \\
& 71.1 & 0.130 & 0.130 & 0.130 \\
& 122.0 & 0.184 & 0.184 & 0.184 \\
$\mathrm{PM}$ & 31.0 & 0.00204 & 0.00204 & 0.00204 \\
& 71.1 & 0.00114 & 0.00114 & 0.00114 \\
& 122.0 & 0.00093 & 0.00093 & 0.00093 \\
\hline
\end{tabular}

oxides and-especially-particulates from cars with compression-ignition engines is significantly higher.

In general, for cars with compression-ignition engines, the sensitivity of road emissions to the traffic model and the conventional size of the vehicle is lower than for cars with spark-ignition engines (Tables 5, 6).

As in the case of specific distance emission, also distance fuel consumption and-as a consequence-operational energy consumption for cars with compressionignition engines are less sensitive to the traffic pattern 
Table 5 Distance fuel consumption and operational energy consumption of cars with spark-ignition engines, from "small", "medium" and "large" segments, under model traffic conditions

\begin{tabular}{|c|c|c|c|c|c|c|}
\hline \multirow{3}{*}{$\begin{array}{l}\mathrm{v}_{\mathrm{AV}} \\
\mathrm{km} / \mathrm{h}\end{array}$} & Small & Medium & Large & Small & Medium & Large \\
\hline & \multicolumn{3}{|l|}{$\mathrm{q}$} & \multicolumn{3}{|l|}{$\mathrm{Q}_{\mathrm{EN}}$} \\
\hline & \multicolumn{3}{|l|}{$\mathrm{g} / \mathrm{km}$} & \multicolumn{3}{|c|}{$\mathrm{kWh} / 100 \mathrm{~km}$} \\
\hline 31.0 & 52.1 & 71.1 & 45.0 & 55.4 & 64.1 & 87.4 \\
\hline 71.1 & 37.2 & 49.1 & 31.6 & 38.9 & 45.8 & 60.4 \\
\hline \multirow[t]{2}{*}{122.0} & 51.7 & 68.2 & 43.9 & 54.1 & 63.6 & 84.0 \\
\hline & Small & Medium & Large & Small & Medium & Large \\
\hline $\mathrm{v}_{\mathrm{AV}}$ & \multicolumn{3}{|l|}{$q$} & \multicolumn{3}{|l|}{$\mathrm{Q}_{\mathrm{EN}}$} \\
\hline $\mathrm{km} / \mathrm{h}$ & \multicolumn{3}{|l|}{$\mathrm{g} / \mathrm{km}$} & \multicolumn{3}{|c|}{$\mathrm{kWh} / 100 \mathrm{~km}$} \\
\hline 31.0 & 52.1 & 68.7 & 42.7 & 51.1 & 62.2 & 82.1 \\
\hline 71.1 & 31.0 & 40.2 & 24.0 & 28.6 & 37.0 & 48.0 \\
\hline 122.0 & 38.6 & 50.0 & 29.9 & 35.7 & 46.1 & 59.8 \\
\hline
\end{tabular}

\begin{tabular}{|c|c|c|c|c|c|c|}
\hline \multirow{3}{*}{$\begin{array}{l}\mathrm{v}_{\mathrm{AV}} \\
\mathrm{km} / \mathrm{h}\end{array}$} & Small & Medium & Large & Small & Medium & Large \\
\hline & \multicolumn{3}{|l|}{$\mathrm{q}$} & \multicolumn{3}{|l|}{$\mathrm{Q}_{\mathrm{EN}}$} \\
\hline & \multicolumn{3}{|l|}{$\mathrm{g} / \mathrm{km}$} & \multicolumn{3}{|c|}{$\mathrm{kWh} / 100 \mathrm{~km}$} \\
\hline 31.0 & 52.1 & 71.1 & 45.0 & 55.4 & 64.1 & 87.4 \\
\hline 71.1 & 37.2 & 49.1 & 31.6 & 38.9 & 45.8 & 60.4 \\
\hline \multirow[t]{2}{*}{122.0} & 51.7 & 68.2 & 43.9 & 54.1 & 63.6 & 84.0 \\
\hline & Small & Medium & Large & Small & Medium & Large \\
\hline $\mathrm{v}_{\mathrm{AV}}$ & \multicolumn{3}{|l|}{$q$} & \multicolumn{3}{|l|}{$\mathrm{Q}_{\mathrm{EN}}$} \\
\hline $\mathrm{km} / \mathrm{h}$ & \multicolumn{3}{|l|}{$\mathrm{g} / \mathrm{km}$} & \multicolumn{3}{|c|}{$\mathrm{kWh} / 100 \mathrm{~km}$} \\
\hline 31.0 & 52.1 & 68.7 & 42.7 & 51.1 & 62.2 & 82.1 \\
\hline 71.1 & 31.0 & 40.2 & 24.0 & 28.6 & 37.0 & 48.0 \\
\hline 122.0 & 38.6 & 50.0 & 29.9 & 35.7 & 46.1 & 59.8 \\
\hline
\end{tabular}

Table 6 Distance fuel consumption and operational energy consumption of cars with compression-ignition engines, from "small", "medium" and "large" segments, under model traffic conditions and the contractual size of the vehicle than for cars with spark-ignition engines.

The comparison between the results obtained on energy consumption and the specific distance emissions associated with the use of internal combustion engine cars with those associated with the use of electric cars are presented in subparagraph 3.3 of this article.

\section{Comparison of energy consumption and pollutant emissions associated with the use of passenger cars with internal combustion engines and passenger cars with electric motors.}

The study [17] presents the results of energy consumption tests by two light-duty trucks: Renault Kangoo ZE (electric motor) and Renault Kangoo Dci (compression-ignition engine). The study was carried out on the roads in the vicinity of Erfurt (Germany), under the following traffic conditions: in city, outside city, on expressways and motorways. Figure 10 shows the dependence between operational energy consumption of the tested cars and their average speed.

There exists a fundamental difference between the electric vehicle and that with the compression-ignition enginethe energy consumption by the car with electric motor is a function of the increasing average speed, whereas in the case of the car with a compression-ignition engine, there occurs the minimum of operational energy consumption under the conditions of driving at the average speed (60-70) $\mathrm{km} / \mathrm{h}$, typical for outside city traffic [20, 21].

Systematic comparison of operational energy consumption of electric cars and cars with Euro 6 combustion engines can be performed on the basis of data on car technical parameters. Table 7 shows basic technical parameters of cars with internal combustion engines: spark ignition (SI) and compression ignition (CI), produced by Nissan, BMW

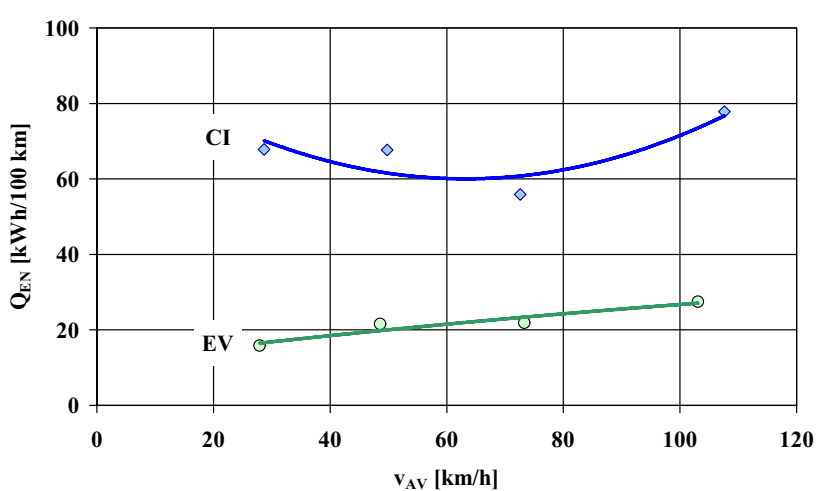

Fig. 10 Dependence between operational energy consumption of the electric car (EV) and the car equipped with compression-ignition engine (CI) and car average speed (based on data from [17])

and Renault. Table 8 presents technical parameters of electric vehicles-car models corresponding to the models of cars with internal combustion engines presented in Table 7. Operational fuel consumption and energy consumption were determined under WLTC test conditions [16].

Figure 11 shows the comparison of operational energy consumption of the passenger cars with electric motor or spark-ignition engine or compression-ignition engine.

Evidently, there is a considerable difference between operational energy consumption of electric cars and that of cars with internal combustion engines.

When compared with cars with spark-ignition engines, the relative reduction in operational energy consumption of electric cars is as follows:

- Nissan-73\%

- $\mathrm{BMW}-68 \%$

- Renault-72\% 
Table 7 Selected technical parameters of Nissan, BMW and Renault passenger cars with spark-ignition (SI) and compression-ignition (CI) engines

\begin{tabular}{|c|c|c|c|}
\hline Parameter & Unit & Nissan Cashquai-SI & $\begin{array}{l}\text { Nissan } \\
\text { Cashquai- } \\
\text { CI }\end{array}$ \\
\hline Engine power & $\mathrm{kW}$ & 120 & 110 \\
\hline Engine torque & $\mathrm{N} \bullet \mathrm{m}$ & 240 & 340 \\
\hline Maximum mass & $\mathrm{kg}$ & 1418 & 1418 \\
\hline Operational fuel consumption & $\mathrm{dm}^{3} / 100 \mathrm{~km}$ & 5.8 & 5.7 \\
\hline \multirow[t]{2}{*}{ Operational energy consumption } & $\mathrm{kWh} / 100 \mathrm{~km}$ & 52.8 & 50.4 \\
\hline & & BMW 1-SI & BMW 1-CI \\
\hline Engine power & $\mathrm{kW}$ & 103 & 140 \\
\hline Engine torque & $\mathrm{N} \cdot \mathrm{m}$ & 220 & 400 \\
\hline Maximum mass & $\mathrm{kg}$ & 1215 & 1215 \\
\hline Operational fuel consumption & $\mathrm{dm}^{3} / 100 \mathrm{~km}$ & 5.7 & 4.6 \\
\hline \multirow[t]{2}{*}{ Operational energy consumption } & $\mathrm{kWh} / 100 \mathrm{~km}$ & 51.9 & 40.7 \\
\hline & & Renault Captur-SI & $\begin{array}{l}\text { Renault } \\
\text { Captur-CI }\end{array}$ \\
\hline Engine power & $\mathrm{kW}$ & 96 & 85 \\
\hline Engine torque & $\mathrm{N} \cdot \mathrm{m}$ & 240 & 260 \\
\hline Maximum mass & $\mathrm{kg}$ & 1250 & 1250 \\
\hline Operational fuel consumption & $\mathrm{dm}^{3} / 100 \mathrm{~km}$ & 5.1 & 3.6 \\
\hline Operational energy consumption & $\mathrm{kWh} / 100 \mathrm{~km}$ & 46.4 & 31.8 \\
\hline
\end{tabular}

Table 8 Selected technical parameters of Nissan, BMW and Renault electric passenger cars

\begin{tabular}{lllll}
\hline Parameter & Unit & Nissan Leaf & BMW 3i & Renault Zoe \\
\hline Engine power & $\mathrm{kW}$ & 160 & 135 & 100 \\
Engine torque & $\mathrm{N} \mathrm{m}$ & 340 & 270 & 245 \\
Maximum mass & $\mathrm{kg}$ & 1490 & 1195 & 1468 \\
$\begin{array}{l}\text { Operational } \\
\text { energy con- }\end{array}$ & $\mathrm{kWh} / 100 \mathrm{~km}$ & 14.4 & 16.5 & 13.2 \\
sumption & & & & \\
\hline
\end{tabular}

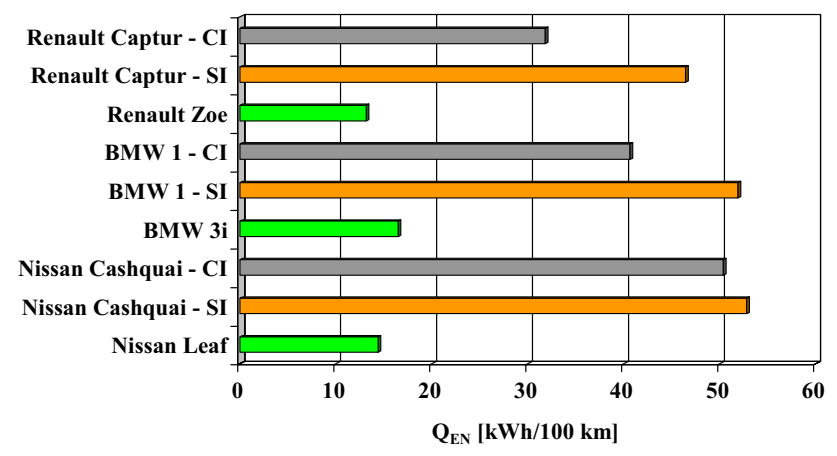

Fig. 11 Operational energy consumption of passenger cars with electric motor or spark-ignition (SI) engine or compression-ignition (CI) engine
In the case of cars with compression-ignition engines, the relative reduction in the operational energy consumption of electric cars is as follows:

- Nissan-71\%

- $\mathrm{BMW}-59 \%$

- Renault-59\%

The differences observed in energy consumption are substantial and clearly indicate that the overall efficiency of electric cars is about three times higher than that of cars with internal combustion engines.

Figures 12-20 present the results of the analysis of energy consumption and pollutant emissions under the conditions of car driving considered at the level of the inventory of pollutant emissions in Poland, obtained based on the model testing (5).

Figures 12, 13 and 14 show the operational energy consumption of "small", "medium" and "large" passenger cars with electric motors, spark-ignition engines and compression-ignition engines, under traffic conditions: in cities, outside cities, on motorways and expressways and throughout the whole period of operation.

Overall, the operational energy consumption of electric cars is significantly lower than that of cars with internal combustion engines in all traffic models and for all vehicle 


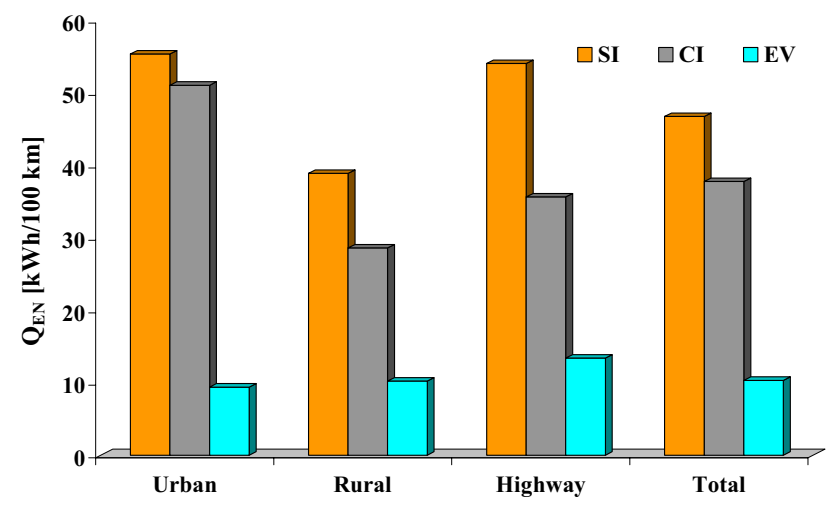

Fig. 12 Comparison of operational energy consumption of passenger cars in "small" segment: electric (EV), with spark-ignition (SI) engine, with compression-ignition (CI) engine, under traffic conditions: in cities, outside cities, on motorways and expressways, and throughout the whole period of operation—-the results of modelling

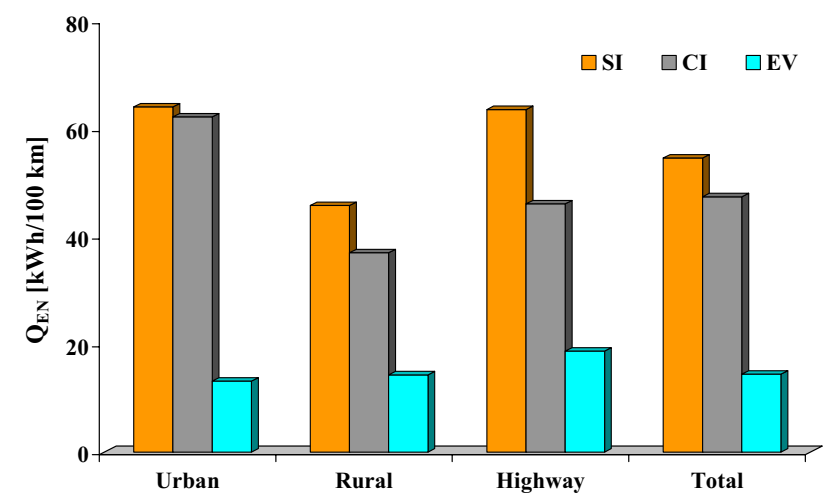

Fig. 13 Comparison of operational energy consumption of passenger cars in "medium" segment: electric (EV), with spark-ignition (SI) engine, with compression-ignition (CI) engine, under traffic conditions: in cities, outside cities, on motorways and expressways, and throughout the whole period of operation - the results of modelling

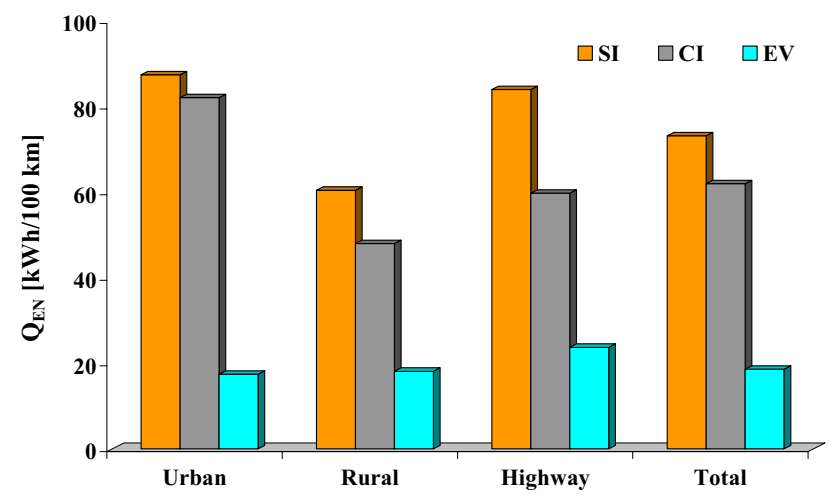

Fig. 14 Comparison of operational energy consumption of passenger cars in "large" segment: electric (EV), with spark-ignition (SI) engine, with compression-ignition (CI) engine, under traffic conditions: in cities, outside cities, on motorways and expressways, and throughout the whole period of operation-the results of modelling segments. Also, clearly visible is the lower operational energy consumption by cars with compression-ignition engines as compared to cars with spark-ignition engines. There is also a noticeable significantly lower operational sensitivity of energy consumption by electric cars to traffic models in comparison to cars with internal combustion engines.

Table 9 shows the relative reduction of operational energy consumption of electric cars as compared to operational energy consumption of cars with spark-ignition or compression-ignition engines, under model traffic conditions for individual car segments. The table also shows the average value of the relative reduction of operational energy consumption for all segments (AV).

The use of electric cars results in the following average relative reduction in energy consumption: over $70 \%$ when compared to cars with spark-ignition engines and almost $70 \%$ when compared to cars with compression-ignition engines. The reduction in energy consumption is higher in urban traffic than in traffic outside cities as well as on motorways and expressways.

The subsequent results of this study show the average values for all the car segments analysed, as well as weighted average of the coefficients applicable to the shares of the distances travelled by cars under the model traffic conditions.

Figure 15 shows the comparison of average operational energy consumption of cars with electric motors or internal combustion engines under traffic conditions throughout the whole period of operation Figs. 16, 17, 18 and 19 show the comparison of the specific distance emission from passenger cars equipped with electric motor or combustion engine under traffic conditions throughout the whole period of operation.

The obtained results show that the difference between the specific distance emissions of carbon dioxide from the cars analysed is not as big as that observed in the case of operational energy consumption. This is due to the relatively high value of the energy factor for carbon dioxide emission during the processes of power generation and transmission.

For non-methane volatile organic compounds, the difference between the cars analysed is substantial-the value of the energy factor for the emission of non-methane volatile organic compounds in the processes of electricity generation and transmission is very low. This results from fuel combustion with considerable air excess in power plantswhich favours the reduction in emissions of the products of incomplete and partial combustion.

In the case of nitrogen oxides, the benefits of using electric cars are lesser than those of cars with compression-ignition engines, as the specific distance emission of nitrogen oxides is lower for cars with spark-ignition engines when compared with electric cars. 
Table 9 Relative decrease in operational energy consumption of electric cars as compared to the operational energy consumption of cars with spark-ignition (SI) or compression-ignition (CI) engines, all car segments studied, under model traffic conditions

\begin{tabular}{|c|c|c|c|c|}
\hline & $\begin{array}{l}\text { Small } \\
\text { SI }\end{array}$ & Medium & Large & AV \\
\hline Urban & $79.6 \%$ & $75.7 \%$ & $77.7 \%$ & $77.6 \%$ \\
\hline Rural & $68.4 \%$ & $63.0 \%$ & $64.8 \%$ & $65.2 \%$ \\
\hline Highway & $70.3 \%$ & $65.1 \%$ & $66.9 \%$ & $67.2 \%$ \\
\hline \multirow[t]{2}{*}{ Total } & $75.1 \%$ & $70.6 \%$ & $72.5 \%$ & $72.6 \%$ \\
\hline & CI & & & \\
\hline Urban & $77.9 \%$ & $75.0 \%$ & $76.2 \%$ & $76.3 \%$ \\
\hline Rural & $57.0 \%$ & $54.2 \%$ & $55.7 \%$ & $55.6 \%$ \\
\hline Highway & $54.9 \%$ & $51.9 \%$ & $53.5 \%$ & $53.3 \%$ \\
\hline Total & $69.2 \%$ & $66.1 \%$ & $67.5 \%$ & $67.5 \%$ \\
\hline
\end{tabular}

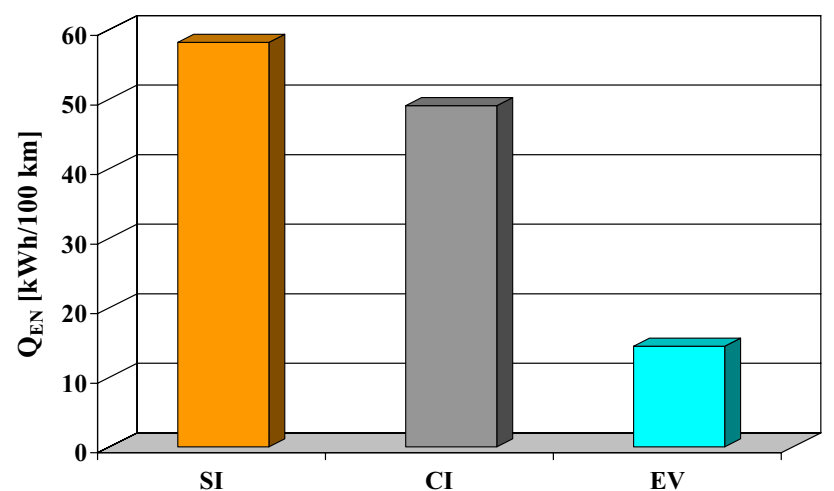

Fig. 15 Average energy consumption of passenger cars: electric (EV), with spark-ignition (SI) or compression-ignition (CI) engines, under traffic conditions throughout the whole period of operation-the results of modelling

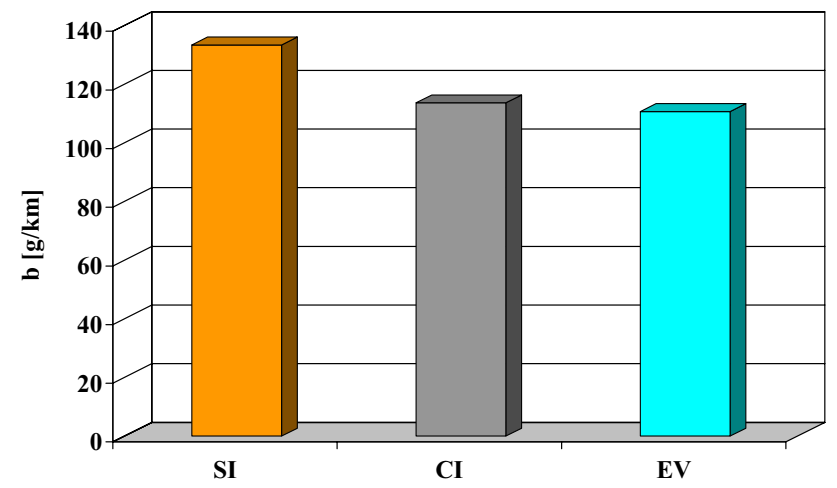

Fig. 16 Specific distance emission of carbon dioxide from passenger cars: electric (EV), with spark-ignition (SI) or compression-ignition (CI) engines, under traffic conditions throughout the whole period of operation - the results of modelling

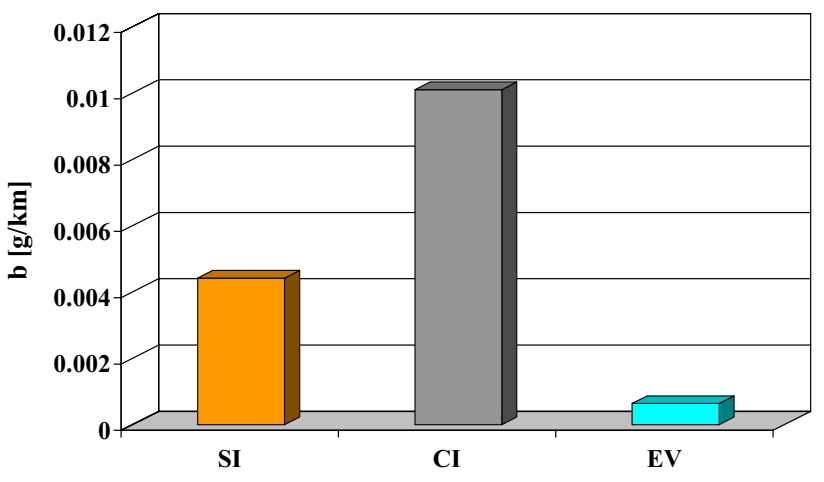

Fig. 17 Specific distance emission of non-methane volatile organic compounds from passenger cars: electric (EV), with spark-ignition (SI) or compression-ignition (CI) engines, under traffic conditions throughout the whole period of operation - the results of modelling

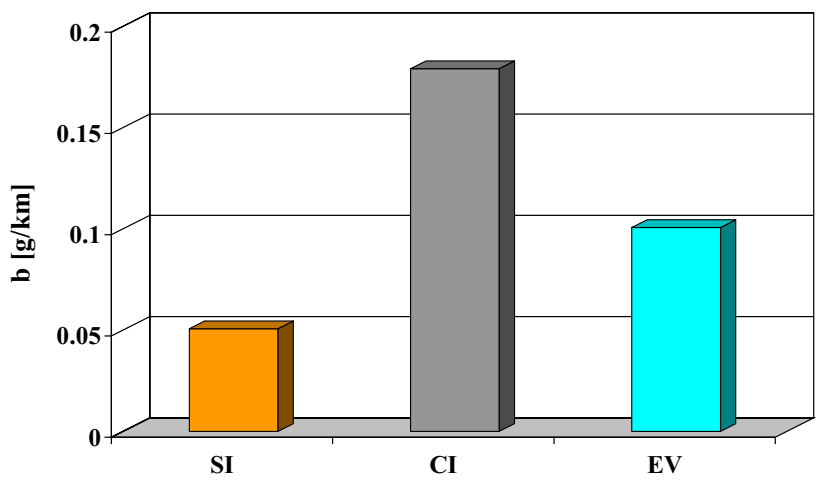

Fig. 18 Specific distance emission of nitrogen oxides from passenger cars: electric (EV), with spark-ignition (SI) or compression-ignition (CI) engines, under traffic conditions throughout the whole period of operation-the results of modelling

Comparison of electric cars with other cars studied in terms of particulate matter emissions shows better performance of cars equipped with internal combustion engines. 


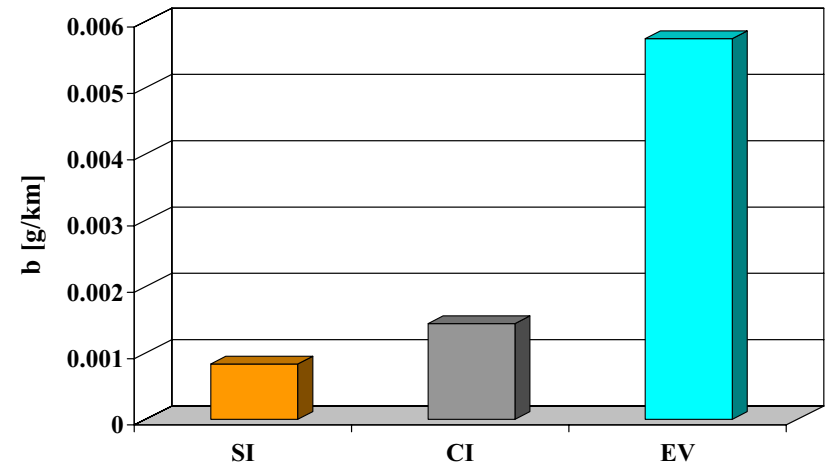

Fig. 19 Specific distance emission of particulate matter from passenger cars: electric (EV), with spark-ignition (SI) or compressionignition (CI) engines, under traffic conditions throughout the whole period of operation-the results of modelling

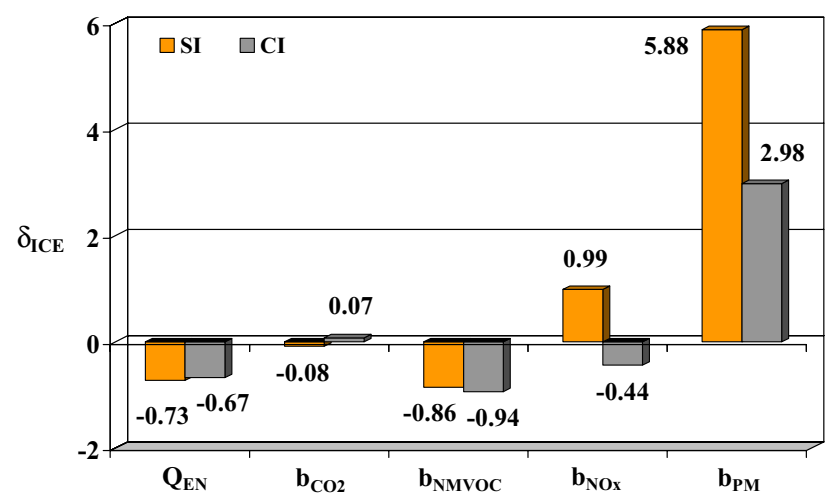

Fig. 20 Relative change in operational energy consumption $\left(Q_{\mathrm{EN}}\right)$ and specific distance emissions of: carbon dioxide $\left(b_{\mathrm{CO} 2}\right)$, non-methane volatile organic compounds $\left(b_{\mathrm{NMVOC}}\right)$, nitrogen oxides $\left(b_{\mathrm{NOx}}\right)$ and particulate matter $\left(b_{\mathrm{PM}}\right)$, from electric cars as compared with cars equipped with spark-ignition (SI) or compression-ignition (CI) engines under traffic conditions throughout the whole period of operation-the results of modelling

This is because of two reasons. First of all, efforts undertaken to reduce particulate matter emissions from internal combustion engines resulted in establishing the limits for specific distance particulate matter emissions, and this led to a several-fold decrease of the limit values for road particulate emissions between the Euro 5 and Euro 6 emission standards [16, 27]. Secondly, electricity generation in Poland is based mainly on solid fuel combustion. As is known, a degree of homogeneity of combusted mixtures of solid fuels is not as good as in the case of liquid fuels (especially gaseous). The combustion processes of solid fuels are heterogeneous by nature and result in unavoidable emission of particulate matter. This is a serious problem in the power industry based on combustion of solid fuels, even with the great progress in the filtration of waste gases from coal power plants.
In order to comprehensively assess the impacts of energy consumption and pollutant emissions of electric cars in use, there was determined the relative change in their operational energy consumption and specific distance emissions. The values obtained were compared with those for cars equipped with spark-ignition and compression-ignition engines:

$\delta_{\mathrm{ICE}}=\frac{w_{\mathrm{EV}}-w_{\mathrm{ICE}}}{w_{\mathrm{ICE}}}$

, where w-physical quantity: $\mathrm{w}=\left[Q_{\mathrm{EN}}, b_{\mathrm{CO} 2}, b_{\mathrm{NMVOC}}, b_{\mathrm{NOx}}\right.$, $\left.b_{\mathrm{PM}}\right]$,

EV-refers to the electric car,

ICE-refers to the car with internal combustion engine: $\mathrm{ICE}=[\mathrm{SI}, \mathrm{CI}] ; \mathrm{SI}-$ spark-ignition engine, $\mathrm{CI}-$ compression-ignition engine.

The effects of the use of electric cars under the conditions at the level of those referred to in the inventory of energy consumption and pollutant emissions, confirms the results of the preceding partial analyses:

- Energy consumption is substantially reduced-by $70 \%$

- Carbon dioxide emissions are affected to a small extent-less than 10\%: the beneficial effect when compared to cars with spark-ignition engines, disadvantageous-when compared to cars equipped with compression-ignition engines

- Emissions of non-methane volatile organic compounds are highly reduced-by $90 \%$

- In terms of nitrogen oxide emissions, electric cars have a big advantage over those with compression-ignition engines; the emissions of nitrogen oxides from cars with spark-ignition engines are about twice as low as compared to electric cars

- Particulate matter emissions act against electric carsthey are about threefold higher than those from cars equipped with compression-ignition engines and almost sixfold higher as compared with spark-ignition engine cars

\section{Conclusion}

The analysis of pollutant emissions and energy consumption of passenger vehicles equipped with the electric motor or the combustion engine compliant with Euro 6 emission standard, carried out for traffic conditions as referred to in Poland's inventory of pollutant emissions and in view of electricity generation and transmission technologies used in the energy sector in Poland, shows the complexity of the assessment of electromobility development impacts on the environment. 
Regardless of beneficial effects of the use of electric vehicles on a local scale, indisputable in terms of emission reduction, the assessment of the situation on a global scale provides no definite answers. The clear benefit of cars with electric motors is the substantial reduction in emissions of organic compounds as compared to internal combustion engine cars. Nonetheless, in the case of the emissions of carbon dioxide and nitrogen oxides, the differences between electric cars and those with combustion engines are quite small. In the case of particulate matter, the emissions from electric cars are comparably increased to a great extent-due to the predominant use of solid fuel (mainly hard coal) combustion technology in Poland's power industry. On the other hand, however, poor performance of electric cars in terms of particulate matter emission when assessed in consideration of energy generation in power plants is highly compensated by zero-emission of particulate matter from EV driving systems, and the risk to human health due to particulate matter emissions on a local scale is incomparably greater than on a global scale.

The undisputable benefit of the use of electric cars is the protection of natural resources, considering the fact that the major reduction of energy consumption is possible due to higher overall efficiency of electric cars as compared to those equipped with combustion engines.

The analyses as regards impacts of electromobility development on the environment can be carried out in a much more comprehensive manner, primarily with the use of the life cycle assessment method. Then, there have to be considered many variable factors and the results obtained may be difficult to interpret. On the other hand, the life cycle assessment can show-except the beneficial effects-numerous adverse environmental impacts of electric cars, especially on a global scale.

\section{Compliance with ethical standards}

Conflict of interest On behalf of all authors, the corresponding author states that there is no conflict of interest.

Open Access This article is licensed under a Creative Commons Attribution 4.0 International License, which permits use, sharing, adaptation, distribution and reproduction in any medium or format, as long as you give appropriate credit to the original author(s) and the source, provide a link to the Creative Commons licence, and indicate if changes were made. The images or other third party material in this article are included in the article's Creative Commons licence, unless indicated otherwise in a credit line to the material. If material is not included in the article's Creative Commons licence and your intended use is not permitted by statutory regulation or exceeds the permitted use, you will need to obtain permission directly from the copyright holder. To view a copy of this licence, visit http://creativecommons.org/licenses/by/4.0/.

\section{References}

1. Chłopek, Z.: Testing of hazards to the environment caused by particulate matter during use of vehicles. Eksploatacja i Niezawodnosc Maint. Reliab. 2, 160-170 (2012)

2. Jakubiak-Lasocka, J., Lasocki, J., Siekmeier, R., Chłopek, Z.: Impact of traffic-related air pollution on health. Environ. Expo. to Pollut. Adv. Exp. Med. Biol. 834, 21-29 (2015)

3. Bebkiewicz, K., Chłopek, Z., Lasocki, J., Szczepański, K., Zimakowska-Laskowska, M.: Inventory of pollutant emission from motor vehicles in Poland using the COPERT 5 software. Combust. Eng. 178(3), 150-154 (2019). https://doi.org/10.19206 /CE-2019-326

4. Chłopek, Z., Lasocki, J.: Comparison of the environmental impact of an electric car and a car with an internal combustion engine in Polish conditions using life cycle assessment method. V Int. Congress on Combust. Eng. 52(3), 192-201 (2013)

5. EMEP/EEA air pollutant emission inventory guidebook 2019. EEA Report. No. 13/2019. Technical guidance to prepare national emission inventories. ISSN 1977-8449 (2019). https:// doi.org/10.2800/293657. https://www.eea.europa.eu/publications/ emep-eea-guidebook-2019. Accessed 26 Oct 2020

6. Poland's informative inventory report 2018. Submission under the UN ECE convention on long-range transboundary air pollution and the DIRECTIVE (EU) 2016/2284. Institute of Environmental Protection - National Research Institute. National Centre for Emission Management (KOBiZE). Warszawa. (2019)

7. Eggleston, S., Buendia, L., Miwa, K., Ngara, T., Tanabe, K. (eds).: IPCC 2006, 2006 IPCC Guidelines for National Greenhouse Gas Inventories, Prepared by the National Greenhouse Gas Inventories Programme. ISBN 4-88788-032-4 (2006). https://www.ipcc-nggip .iges.or.jp/public/2006gl/. Accessed 26 Oct 2020

8. Bebkiewicz, K., Chłopek, Z., Lasocki, J., Szczepański, K., Zimakowska-Laskowska, M.: Analysis of emission of greenhouse gases from road transport in Poland between 1990 and 2017. Atmos. 11(4), 387 (2020). https://doi.org/10.3390/atmos 11040387

9. Poland's national inventory report 2019. Greenhouse gas inventory for 1988-2017. Submission under the UN framework convention on climate change and its kyoto protocol. Institute of Environmental Protection - National Research Institute. National Centre for Emission Management (KOBiZE). Warszawa. (2019)

10. USA Environmental Protection Agency: 2017 National Emissions Inventory Complete Release. Technical Support Document (2020). https://www.epa.gov/sites/production/files/2020-04/ documents/nei2017_tsd_full_30apr2020.pdf. Accessed 26 Oct 2020

11. Chłopek, Z., Dębski, B., Szczepański, K.: Theory and practice of inventory pollutant emission from civilization-related sources: share of the emission harmful to health from road transport. Arch. Automot. Eng-Arch. Motoryz. 79(1), 5-22 (2018)

12. European Union emission inventory report 1990-2017 under the UNECE convention on long-range transboundary air pollution (LRTAP) 1994-2019. EEA Report No 08/2019

13. KOBiZE. Wskaźniki emisyjności $\mathrm{CO} 2, \mathrm{SO} 2, \mathrm{NOx}, \mathrm{CO}$ i pyłu całkowitego dla energii elektrycznej na podstawie informacji zawartych w,Krajowej bazie o emisjach gazów cieplarnianych i innych substancji za 2018 rok". (2019)

14. Chłopek, Z., Lasocki, J., Wójcik, P., Badyda, A.: Experimental investigation and comparison of energy consumption of electric and conventional vehicles due to the driving pattern. Int. J. Green Energy 15(13), 773-779 (2018)

15. Ivanov, R., et al.: Energy characteristics of Citroen Berlingo converted to electric vehicle. Transp. Probl. 13(3), 151-161 (2018). https://doi.org/10.20858/tp.2018.13.3.14 
16. Worldwide emission standards. Heavy duty \& off-road vehicles. Delphi. Innovation for the real world. (2017)

17. Braun, A., Rid, W.: Energy consumption of an electric and an internal combustion passenger car a comparative case study from real world data on the erfurt circuit in Germany. Transport. Res. .Proced. 27, 468-475 (2017)

18. Wu, X., et al.: Electric vehicles' energy consumption measurement and estimation. Transport. Res. Part D Trans. Environ. (2015). https://doi.org/10.1016/j.trd.2014.10.007

19. Ricardo-AEA. Update of the handbook on external costs of transport. Final Report for the European Commission: DG MOVE. Ricardo-AEA/R/ ED57769 (1). 8th Jan (2014)

20. Chłopek, Z., Biedrzycki, J., Lasocki, J., Wójcik, P.: Examination of pollutant emissions and fuel consumption at tests simulating the real conditions of operation of a passenger car. Arch. Automot. Eng. Arch Motoryz. 65(3), 3-18 (2014)

21. INFRAS AG. Handbuch fur Emissionsfaktoren des Strassenverkehrs; Version 3.1; Bern (2010)

22. KOBiZE. Wartości opałowe (WO) i wskaźniki emisji CO2 (WE) w roku 2016 do raportowania w ramach Systemu Handlu Uprawnieniami do Emisji za rok 2019. Warszawa (2018)
23. Chłopek, Z.: Research on energy consumption by an electrically driven automotive vehicle in simulated urban conditions. Eksploat. i Niezawodn. Maint. Reliab. 15(1), 75-82 (2013)

24. Wang, J., Besselink, I., Nijmeijer, H.: Battery electric vehicle energy consumption prediction for a trip based on route information. Proc. IMech. Eng. Part D: J. Automob. Eng. 232(11), 1528-1542 (2018). https://doi.org/10.1177/0954407017729938

25. Chłopek, Z., Piaseczny, L.: Remarks about the modelling in science researches. Eksploat. i Niezawodn. Maint. Reliab. 11(4), 47-57 (2001)

26. Achiezer, N.I.: Theory of approximation. Ungar, New York (1956)

27. Worldwide emission standards. Passenger cars and light duty vehicles. Delphi. Innovation for the real world. (2019)

Publisher's Note Springer Nature remains neutral with regard to jurisdictional claims in published maps and institutional affiliations. 